\title{
Nieniszczące badania kolumny żelbetowej w wielokondygnacyjnym budynku użyteczności publicznej
}

\author{
Non-destructive tests of a damaged \\ reinforced concrete column in a multi-storey public utility building
}

\section{Streszczenie}

Kolumna żelbetowa podpierająca narożną część wielokondygnacyjnego budynku posiadała liczne rysy mogące świadczyć o jej przeciążeniu (zagrożeniu bezpieczeństwa konstrukcji). W celu zdiagnozowania jej stanu technicznego wykonano szereg badań nieniszczących, głównie ultradźwiękowych, na podstawie których ustalono: położenie zbrojenia, grubość warstwy uszkodzonej (popękanej), głębokość rys o różnych rozwartościach na powierzchni. Stosowano dwa typy głowic ultradźwiękowych: walcowe z dużą powierzchnią kontaktową wymagającą stosowania środka sprzęgającego oraz głowice punktowe przekazujące drgania ultradźwiękowe do betonu bez takiego środka. Metodykę i zakres badań korygowano w trakcie pomiarów, w nawiązaniu do odkrywanych defektów i poznawanej technologii wykonywania kolumny a zwłaszcza sposobu nagrzewania betonu. Zastosowanie głowic punktowych umożliwiło, między innymi zbadanie rdzenia kolumny i wykazanie, że nie posiada on uszkodzeń widocznych na powierzchni.

Słowa kluczowe: beton; rysy; uszkodzenia; ultradźwięki

\begin{abstract}
The reinforced concrete column supporting a corner part of a multi-storey building had numerous crevices which could indicate its overloading (risk for safety of the structure). In order to diagnose its technical condition, a number of non-destructive, mainly ultrasound, tests were performed on the grounds of which the following was determined: location of reinforcement, thickness of the damaged (cracked) layer, depth of crevices having various widths on the surface. Two types of ultrasound heads were used: cylindrical ones with large contact area requiring application of a coupling agent and spot heads transmitting ultrasound vibrations to concrete without such agent. The methodology and scope of tests were corrected during the measurements appropriately to discovered defects and established technology of making the columns, in particularly the method of heating concrete. Application of the spot heads made it possible, among other things, to test the column core and to prove that it does not have any damage visible on the surface.
\end{abstract}

Keywords: concrete; crevices; damage; ultrasound

\section{Wstęp}

Beton i żelbet obok stali w dalszym ciągu są dominującymi materiałami stosowanymi do wznoszenia budynków. Badanie najważniejszego parametru jakim jest wytrzymałość na ściskanie jest znormalizowana, ale normowy sposób nie uwzględnia technologii wykonania, która może doprowadzić do tego, że ten najważniejszy parametr jest diametralnie inny (zwykle niższy)

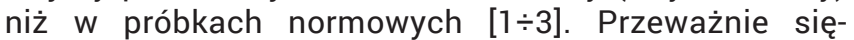
gamy wtedy do metod nieniszczących aby określić np. wytrzymałość materiału w konstrukcji. Gdy dodatkowo występują uszkodzenia, takie jak rysy, pęknięcia, to ocena bezpieczeństwa konstrukcji komplikuje się. Mamy wprawdzie bardzo wyspecjalizowane nowoczesne urządzenia do wykrywania wad w betonie, np. tomograf ultradźwiękowy [4] metoda impact echo i inne [5,6], jednak zastosowanie ich w konkretnym przypadku wymaga spełnienia dość ostrych wymagań np. musi być dość duża płaska powierzchnia do badania albo wada musi być w pewnym oddaleniu od powierzchni itp. Ostatecznie najczęściej zastosowanie klasycznej metody ultradźwiękowej z głowicami płaskimi lub punktowymi pozwala najlepiej rozpoznać stan badanej konstrukcji, uzyskać najwięcej potrzebnych informacji. Taki przypadek prezentowany jest w artykule. Szczególny nacisk położono na indywidualne podejście do badań i pogłębioną analizę samego tworzywa jakim jest beton z uwzględnieniem technologii zastosowanej do wykonania badanej konstrukcji.

Prof. nzw. dr hab. inż. Bohdan Stawiski - Uniwersytet Zielonogórski, Wydział Budownictwa, Architektury i Inżynierii Środowiska.

Autor korespondencyjny/Corresponding author: bohdan.stawiski@pwr.edu.pl 


\section{Opis badanej konstrukcji}

Jeden ze słupów żelbetowych podtrzymujący wielokondygnacyjny budynek po rozformowaniu wykazywał szereg niepokojących rys o różnym przebiegu, różnej rozwartości i różnej długości (rys. 1).

Słup podpiera narożną część budynku co wzbudziło jeszcze większy niepokój. Pojawiło się szereg pytań, w pierwszej kolejności o wytrzymałość betonu tym bardziej, że powierzchna słupa nie była jednorodna (obszary jaśniejsze i ciemniejsze), obniżona wytrzymałość wpłynęłaby na obniżenie nośności słupa, inne pytania dotyczyły głębokości rys, ich przebiegu (czy przechodzą przez cały słup czy są powierzchniowe itd.). Co było przyczyną pojawienia się opisanych wyżej defektów, jak je usunąć, jak naprawić wadliwy i bardzo ważny element konstrukcyjny?
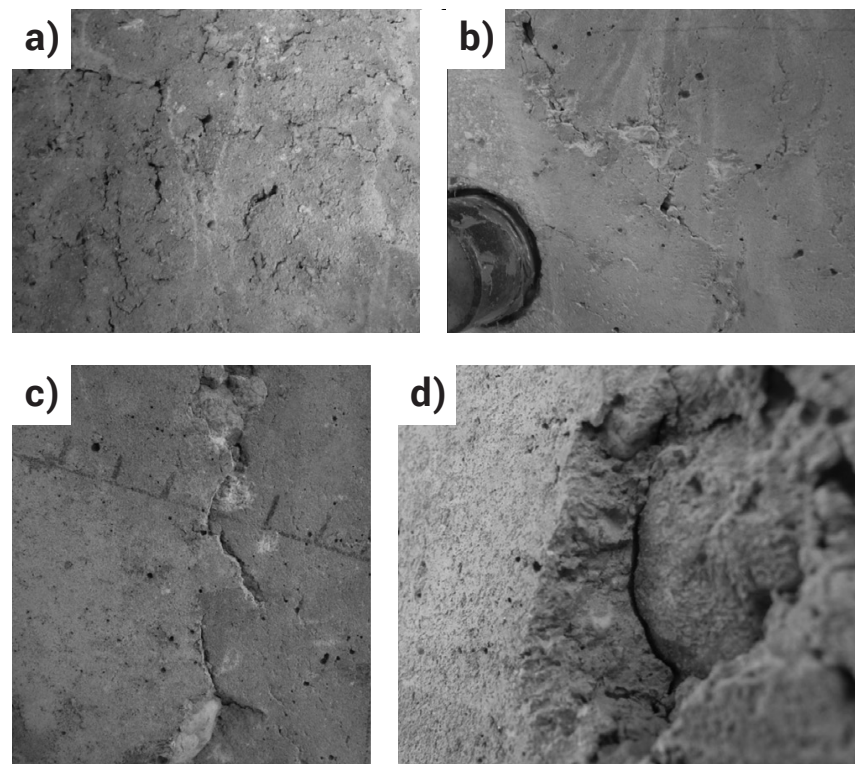

Rys. 1. Wady widoczne na powierzchni badanego słupa żelbetowego a) rysy drobne przebiegające w różnych kierunkach, b) rysy ukośne w stosunku do osi słupa, c) rysa pionowa o dużej rozwartości, d) odsłonięte ziarna grubego kruszywa

Fig. 1. Defects visible on the surface of the reinforced concrete column: a) minor crevices running in various directions, b) crevices sloping versus the column axis, c) vertical crevice of considerable width, d) uncovered grains of coarse aggregate

\section{Nieniszczące badania słupa}

Uszkodzony słup został już częściowo obudowany ścianami, co dodatkowo utrudniło badania (rys. 2).

Pierwszym krokiem w diagnostyce było zbadanie położenia zbrojenia w słupie. Zadanie to bez problemu zrealizowano metodą elektromagnetyczną przy pomocy Covemetru. Okazało się, że grubość otuliny jest różna na obwodzie kolumny i waha się od $17 \mathrm{~mm}$ do $50 \mathrm{~mm}$ (rys. 2). Uszkodzenia słupa polegające na spękaniu betonu były największe tam, gdzie otulina była najcieńsza.

Następne próby diagnostyczne dotyczyły jakości betonu na powierzchni. Badania wykonano metodą ultradźwiękową z wykorzystaniem głowic punktowych, które pozwalają na badanie materiału na dowolnie małych odcinkach (pomiędzy rysami). Badana $w$ ten sposób fala powierzchniowa charakteryzowała się jednak dużymi rozrzutami, co wskazywało na występowanie w betonie nie tylko rys o dużej rozwartości (widocznych gołym okiem) ale także mikropęknięć niewidocznych z powierzchni. Uzyskano w ten sposób potwierdzenie, że beton w powierzchniowej strefie kolumny

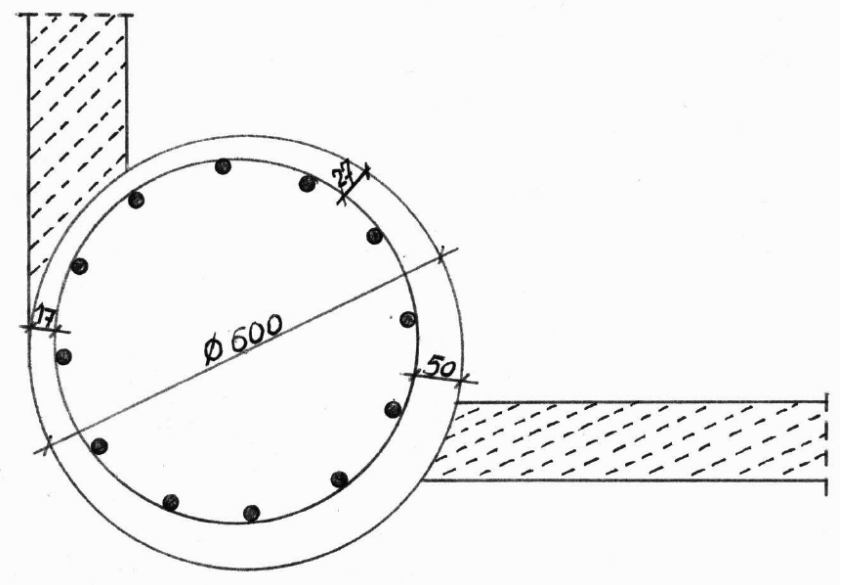

Rys. 2. Usytuowanie słupa między ścianami. Na przekroju zaznaczono położenie przesuniętego zbrojenia

Fig. 2. Location of the column between walls making ultrasound tests difficult. Location of the relocated reinforcement marked in the cross-section

ma tylko lokalnie wytrzymałość na oczekiwanym poziomie, na większych odcinkach już tak nie jest, nie spełnia również funkcji ochronnej przed korozją dla stali zbrojeniowej. Nie uzyskano w dalszym ciągu informacji o betonie w głębi kolumny. Warto w tym miejscu wspomnieć, że o nośności słupa decyduje stal zbrojeniowa i beton zawarty w rdzeniu. Otulina spełnia tylko funkcję ochronną dla zbrojenia, nie ma jednak wpływu na nośność kolumny. Zastosowano więc ultradźwiękową metodą przepuszczania. Wybrano głowice walcowe o niskiej częstotliwości $40 \mathrm{kHz}$, o średnicy $40 \mathrm{~mm}$. Do sprzężenia akustycznego stosowano wazelinę techniczną. Badania takie (rys. 3) wykonano dla uszkodzonej kolumny a także dla dwóch innych o takiej samej średnicy, zabetonowanych w tym samym czasie lecz nie wykazujących wad powierzchniowych.

a)

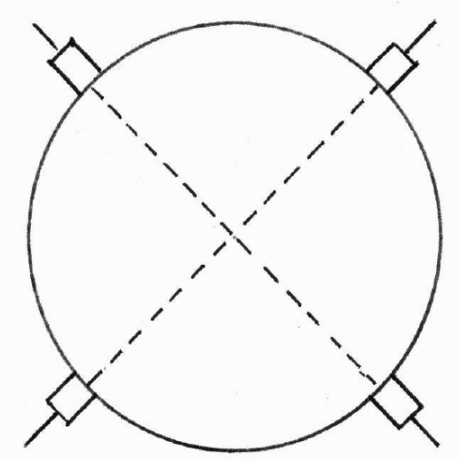

b)

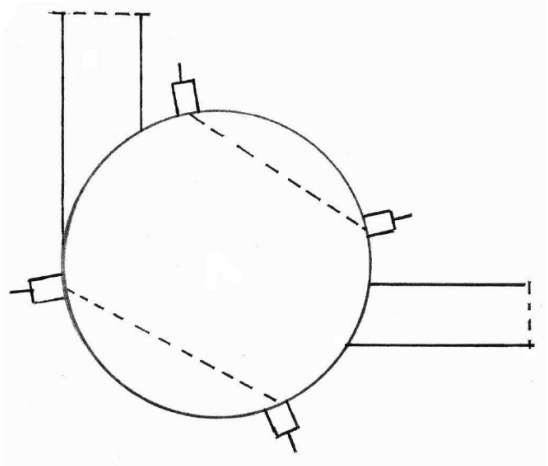

Rys. 3. Sposób badania kolumn metodą przepuszczania, a) wzdłuż średnicy, b) wzdłuż cięciwy

Fig. 3. Method of testing the columns using the inline method: a) along the diameter, b) along the chord 
Tablica I. Prędkość ultradźwiękowej fali podłużnej $C_{L}$ w badanych kolumnach Table I. Velocity of longitudinal ultrasound wave $C_{L}$ in the tested columns

\begin{tabular}{|c|c|c|c|c|c|}
\hline Nr kolumny & Nr punktu pomiaru & Cięciwa [mm] & Średnicy [mm] & $\begin{array}{c}\text { Czas przejścia } \\
{[\mu \mathrm{s}]}\end{array}$ & $\begin{array}{c}\text { Prędkość fali } C_{\mathrm{L}} \\
{[\mathrm{km} / \mathrm{s}]}\end{array}$ \\
\hline 1 popękana & $\begin{array}{l}1 \\
2 \\
3 \\
4 \\
5 \\
6 \\
7 \\
8 \\
9 \\
10\end{array}$ & $\begin{array}{l}490 \\
495 \\
495 \\
480 \\
510 \\
515 \\
515\end{array}$ & $\begin{array}{l} \\
600 \\
600 \\
600\end{array}$ & $\begin{array}{c}- \\
276,2 \\
269,4 \\
356,7 \\
- \\
432,1 \\
265,2 \\
168,2 \\
241,2 \\
391,3\end{array}$ & $\begin{array}{c}- \\
2,17 \\
2,22 \\
1,68 \\
- \\
1,38 \\
2,26 \\
3,57 \\
2,49 \\
1,53\end{array}$ \\
\hline 2 bez uszkodzeń & $\begin{array}{l}1 \\
2 \\
3\end{array}$ & & $\begin{array}{l}600 \\
600 \\
600\end{array}$ & $\begin{array}{l}142,0 \\
163,3 \\
169,9\end{array}$ & $\begin{array}{l}4,24 \\
3,67 \\
3,64\end{array}$ \\
\hline 3 bez uszkodzeń & $\begin{array}{l}1 \\
2 \\
3\end{array}$ & & $\begin{array}{l}600 \\
600 \\
600\end{array}$ & $\begin{array}{l}163,2 \\
139,4 \\
138,7\end{array}$ & $\begin{array}{l}3,69 \\
4,30 \\
4,33\end{array}$ \\
\hline
\end{tabular}

Pomierzone prędkości fali CL w słupach 2 i 3 (bez uszkodzeń) są wysokie. W słupie nr 1 (z uszkodzoną warstwą betonu) wyniki są różnorodne, tylko na jednym odcinku pomiarowym (nr 8) prędkość była podobna określonej w słupach bez uszkodzeń. Tak duże rozrzuty wyznaczonej prędkości można wytłumaczyć omijaniem przez impuls ultradźwiękowy rys na drodze przejścia (rys. 4).

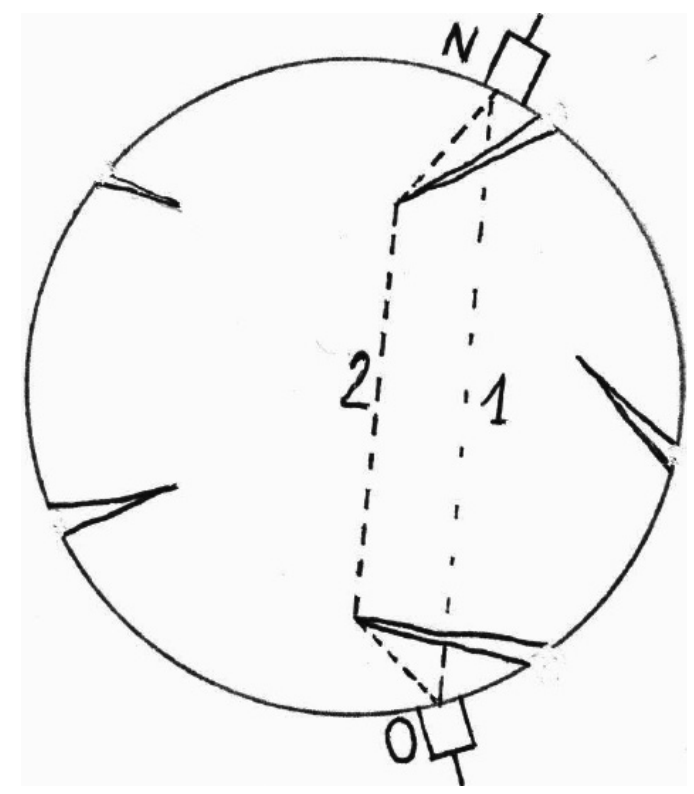

Rys. 4. Teoretyczna droga przepływu impulsu $I_{1}(1)$ i rzeczywista droga przepływu impulsu $I_{2}(2), l_{2}>>I_{1}$

Fig. 4. Theoretical path of flow for impulse $I_{1}(1)$ and actual but not determined path of flow for impulse bypassing crevices $I_{2}(2), I_{2}>>I_{1}$
Reasumując trzeba stwierdzić, że i ta metoda badania nie dała odpowiedzi na temat jakości betonu w wewnętrznej strefie kolumny.

Dążąc jednak do postawienia zweryfikowanej diagnozy podjęto dalsze kroki badawcze.

Ważną informacją byłaby znajomość głębokości rys widocznych na powierzchni. Metoda ultradźwiękowa nadaje się do takich pomiarów, jednak nie można liczyć na dużą dokładność, gdyż prędkość fali podłużnej w warstwie powierzchniowej może być obarczona błędem wynikającym z spękania tej warstwy. Nie licząc więc na dużą dokładność wykonano jednak takie badania. Głowice punktowe przykładano do kolumny wzdłuż linii prostopadłej do rysy w odległościach 10, 20, $30 \mathrm{~mm}$.

$$
\mathrm{y}_{\mathrm{n}}=\sqrt{\left.\left(\mathrm{t}_{\mathrm{n}} \mathrm{C}_{\mathrm{L}}\right) / 2\right)^{2}+\left(\mathrm{X}_{\mathrm{n}} / 2\right)^{2}}
$$

gdzie:

$t_{n}$ - czas przejścia fali ultradźwiękowej od nadajnika $\mathrm{N}$ do odbiornika $O$ przy położeniu głowic $w$ odległości $X_{n}$,

$\mathrm{X}_{\mathrm{n}}$ - odległość między głowicami,

$\mathrm{C}_{\mathrm{L}}$ - prędkość fali ultradźwiękowej

Jako przeciętną prędkość fali CL przyjęto wartość $2,2 \mathrm{~km} / \mathrm{s}$ (tabl. I). Obliczona w ten sposób głębokość rys wynosiła 12,8 $\mathrm{mm}$ do $32,3 \mathrm{~mm}$. W jednym przypadku głębokość rysy wynosiła 55,0 mm. Okazało się, że rysy dochodzą do rdzenia kolumny, mieszczącego się między zbrojeniem.

W celu potwierdzenia powyższego wniosku wykonano dodatkowe pomiary metodą przepuszczania ultradźwięków przez betonowy rdzeń kolumny. W tym celu nawiercono otwory z dwóch stron słupa przechodzące przez popękaną otulinę (rys. 6). 

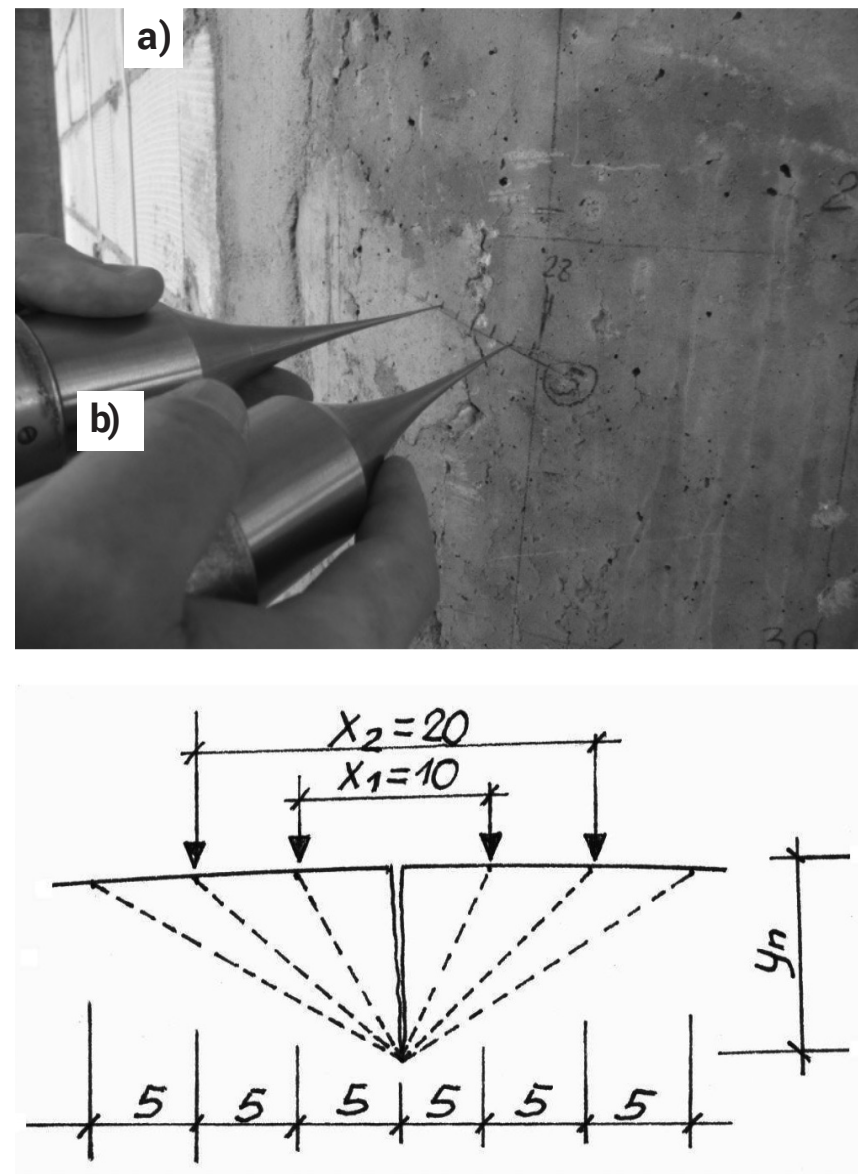

Rys. 5. Sposób wyznaczania głębokości rysy gdy jest ona prostopadła do powierzchni: a) teoretyczny przebieg impulsu od nadajnika $\mathrm{N}$ do odbiornika $\mathrm{O}, \mathrm{b}$ ) wykonywanie pomiaru

Fig. 5. Method of determining depth of the crevice where it is perpendicular to the surface: a) theoretical flow of the impulse from transmitter $T$ to receiver $R, b$ ) performance of the measurement

Prędkość ultradźwięków w betonie rdzenia $(3,6 \div 3,8 \mathrm{~km} / \mathrm{s})$ była zbliżona do prędkości określonej na kolumnach 2 i 3 bez uszkodzeń.

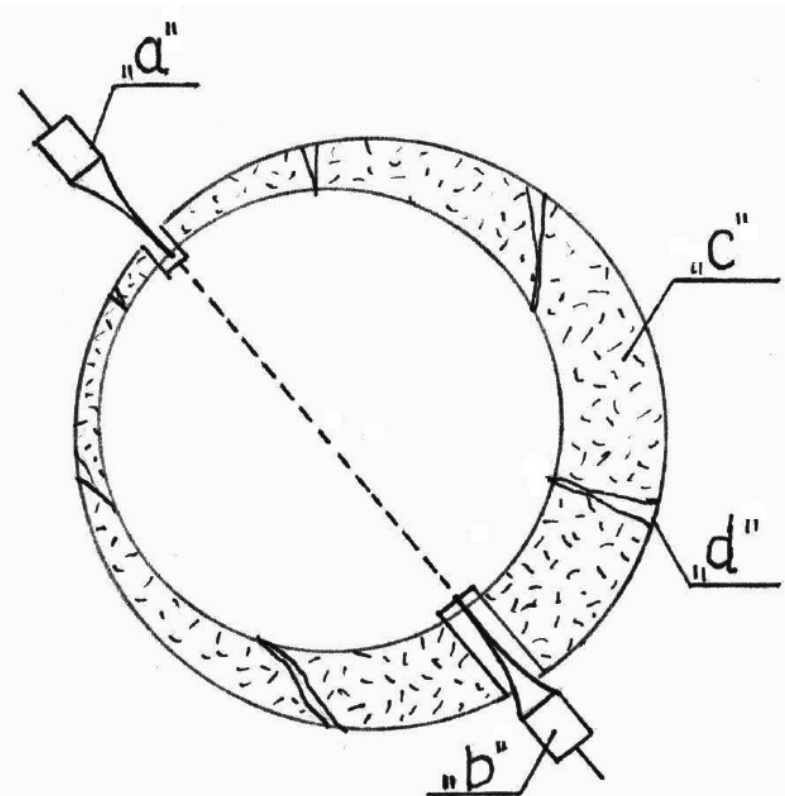

Rys. 6. Sposób badania rdzenia kolumny metodą przepuszczania ultradźwięków: a) głowica nadawcza, b) głowica odbiorcza, c) strefa powierzchniowa popękana, d) rysa do zbrojenia

Fig. 6. Method of testing the column core using the inline method: a) transmitting (spot) head, b) receiving spot head, c) surface cracked zone, d) crevice reaching the reinforcement

\section{Przyczyny powstałych uszkodzeń}

Ustalony w badaniach obszar występujących uszkodzeń wskazuje przyczynę spękań. Okazało się, że betonowanie słupa wykonano przy ujemnych temperaturach otoczenia. Aby podwyższyć temperaturę betonu zastosowano podgrzewanie elektryczne. Do zbrojenia podłączono prąd elektryczny o obniżonym napięciu i dużym natężeniu. Nagrzew nie był dobrze kontrolowany. Nadmiernie nagrzane pręty zbrojeniowe powiększyły swoją objętość i doprowadziły do rozrywania betonu w strefie zewnętrznej rozciąganej. Strefa wewnętrzna była ściskana i ona nie uległa istotnym uszkodzeniom.

\section{Podsumowanie}

Zastosowanie nieniszczących metod badania było jedynym sposobem do zdiagnozowania stanu technicznego kolumny podtrzymującej narożną część wielokondygnacyjnego budynku. Warto zwrócić uwagę na przedstawiony sposób dochodzenia do wniosków końcowych. Wykonując schematycznie badania ultradźwiękowe metodą przepuszczania (według zaleceń normowych) uzyskano by wynik negatywny, nie odzwierciedlający rzeczywistego stanu konstrukcji. Indywidualna, nieschematyczna interpretacja wyników jest szczególnie ważna podczas badań nieniszczących. W omawianym przypadku dopiero połączenie wyników pomiarów ultradźwiękowych z technologią wykonania i znajomością wpływu obróbki termicznej betonu na jego własności dało podstawy do zdiagnozowania rzeczywistego stanu konstrukcji. Bardzo przydatne okazało się również zastosowanie głowic punktowych, które w wielu przypadkach ułatwiają badania ultradźwiękowe [7].

\section{Literatura}

[1] PN-EN 206-1. Beton, wymagania, właściwości, produkcja i zgodność.

[2] PN-EN 13791. Ocena wytrzymałości betonu na ściskanie w konstrukcjach i prefabrykowanych wyrobach betonowych.

[3] PN-EN 12504-1 Badania betonu w konstrukcjach. Cz. 1 Odwierty rdzeniowe.

[4] Hoła J., Schabowicz K.: Diagnostyka obiektów budowlanych, Materiały Budowlane nr 5/2015, s. $3-7$
[5] Drobiec Ł., Jasiński R., Piekarczyk A.: Diagnostyka konstrukcji żelbetowych. PWN, Warszawa 2010.

[6] Bungey J. H., Millard S. G., Grantham M. G.: Testing of Concrete in Structures. Taylor \& Francis. London and New York, 2006.

[7] Stawiski B.: Ultradźwiękowe badania betonów i zapraw głowicami punktowymi. Oficyna wydawnicza Politechniki Wrocławskiej. Wrocław 2009. 